\title{
Laparoscopic appendectomy with hand-made loop
}

\author{
Burhan Mayir, Tuna Bilecik, Cemal Ozben Ensari, Mehmet Tahir Oruc \\ Department of General Surgery, Antalya Training and Research Hospital, Antalya, Turkey
}

Videosurgery Miniinv 2014; 9 (2): 152-156

DOI: $10.5114 /$ wiitm.2014.41624

\begin{abstract}
Introduction: Acute appendicitis is the most common abdominal pathology requiring emergent surgical procedure. For treatment, laparoscopic surgery is commonly performed. For appendix stump closure different procedures are used.

Aim: Evaluation of the results of patients in whom the stump of the appendix was closed with a hand-made loop during laparoscopic appendectomy (LA).

Material and methods: Patients in whom the stump of the appendix was closed with a hand-made loop during LA were included in the study. Reports of patients were collected from patient files retrospectively. Laparoscopic appendectomy was applied through 3 ports. Two loops were placed in the stump of the appendix. Loop was a modification of the Roeder loop that has been described in the literature and has been shown to be safe.

Results: Sixty-one patients were included in the study. Twenty-four of them (39\%) were female, 37 of them (61\%) were male. The age range is from 13 to 60 (average age is 30) years. During the postoperative period, one surgical wound infection and two intraabdominal abscesses were detected. There was no leakage from the stump of the appendix in any patients.

Conclusions: One of the most important components of cost of LA is the technique of closure of the stump. Stapler, endoloop, various clips or a hand-made loop could be used for closure. We recommend using a hand-made loop for closure as an easy, safe and cheap method.
\end{abstract}

Key words: laparoscopic appendectomy, hand-made loop, acute appendicitis.

\section{Introduction}

The most common abdominal emergent surgical procedure is acute appendicitis. For treatment laparoscopic appendectomy (LA) can be preferred, which was first described by Semm in 1983. The procedure is especially recommended for women, old and obese patients. It has some advantages when compared with open appendectomy such as causing less pain, a shorter period to get to work, shorter length of stay in hospital, and better cosmetic results [1, 2]. Disadvantages of the procedure are longer time of operation, higher rate of developing intraabdominal abscess and higher cost $[3,4]$. To lower costs, some methods have been tried such as using two ports, closing the stump with clips, and an extracorporeal sliding knot $[5,6]$. Another way of lowering costs is preferring a handmade loop instead of an endoloop or stapler.

\section{Aim}

The aim of this study was to evaluate retrospectively the results of patients in whom a hand-made loop is preferred during LA.

\section{Material and methods}

In this study, we included patients in whom a handmade loop is used during laparoscopic surgery of

\section{Address for correspondence:}

Burhan Mayir MD, Department of General Surgery, Antalya Training and Research Hospital, Antalya Egitim ve Arastirma Hastanesi,

07070 Antalya, Turkey, phone: 242 2494400, e-mail: burmay@yahoo.com 
acute appendicitis. Gender, age, information about the operation, and complications related to the operation were collected from patients' files. Purulent fluid collection in the abdomen was defined as intraabdominal abscess. Purulent discharge from incision or erythema on incision were defined as surgical wound infection.

All operations were performed by the same surgical team. All patients received antibiotics preoperatively. The first $10 \mathrm{~mm}$ port was placed subumbilically under direct vision; afterwards one $5 \mathrm{~mm}$ port was placed suprapubically and one $10 \mathrm{~mm}$ port was placed in the left lower quadrant of the abdomen. Patients were lying in the 15-20-degree Trendelenburg position, tilted $10-15^{\circ}$ to the left side. Mesentery of appendix was cut after coagulation, then two loops were replaced to the base of the appendix, which were prepared extracorporeally with $2 / 0$ polyglactin. There was $1-2 \mathrm{~mm}$ distance between two loops (Photo 1). Afterwards the appendix was cut above the loops and retrieved through the left lower quadrant port. Our loop is a modified type of the Tayside knot that is commonly used [7]. For preparation of this loop, first the suture is curled as a circle and a usual knot is tied at the base of the loop (Photo 2 A). One short and one long limb were created after placing the knot. We formed a second smaller loop with a short limb and wrapped the short limb 4 times around the long limb (Photo $2 \mathrm{~B}$ ), then we passed the terminal end of the short limb inside the small loop we had formed secondly (Photo $2 \mathrm{C}$ ) and tightened the loop (Photo $2 \mathrm{D}$ ). The prepared loop was pushed inside the abdomen through the port, leaving the long limb outside. After the loop was placed on the base of the appendix, the knot of the loop was tightened by a grasper.

\section{Results}

Sixty-one patients were included in the study. Twenty-four (39\%) of them were female, 37 (61\%) of them were male. Average age was 30 , ranging from 13 to 60. All patients were operated as described before.

There was no need for additional loop or stapler use or conversion to open procedure. After $8 \mathrm{~h}$ of operation, all patients began oral intake. The period of stay in hospital was 1.3 (1-2) days. During the post-operative period, one surgical wound infection
(1.6\%) and two intraabdominal abscesses (3.2\%) were detected. When those 2 patients were operated on again, abscess in the Douglas pouch was detected, while the stump of the appendix and cecum were normal. There was no leakage from the stump of the appendix in any patient. At the histopathological examination, 7 (11\%) specimens were diagnosed as a normal appendix.

\section{Discussion}

Laparoscopic appendectomy is becoming an important choice of treatment for acute appendicitis after widespread use of laparoscopy. But this approach entails higher costs of treatment. There are many studies showing that laparoscopic surgery causes higher costs compared with open appendectomy $[8,9]$. For this reason, some surgeons have tried to decrease the number of ports or other surgical instruments used in the operation to reduce costs [10]. In some studies, it has been reported that closing the stump of the appendix with materials other than a stapler or endoloop could lower the costs. Although studies are limited, it has been reported that the stump of the appendix can be closed safely with clips, with extracorporeal sliding knots or with hand-made loops [11, 12].

Closure of the stump of the appendix with a stapler is a simple but more expensive method when compared with others [4-6, 13]. Closure with endoloop is a common way and has a lower cost than a stapler [4]. Some authors have described various clips for closure that are easier and cheaper. Partecke et al. demonstrated that using nonab-

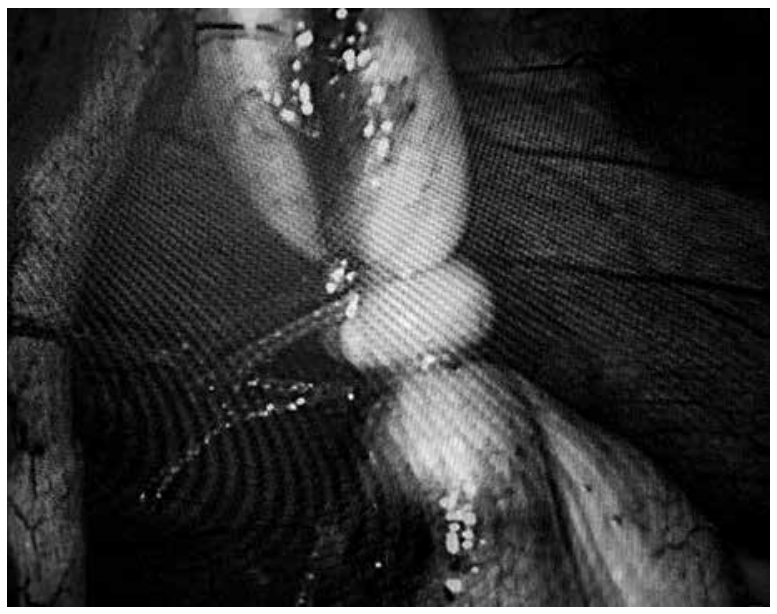

Photo 1. Two tightened loops on stump of appendix 
A

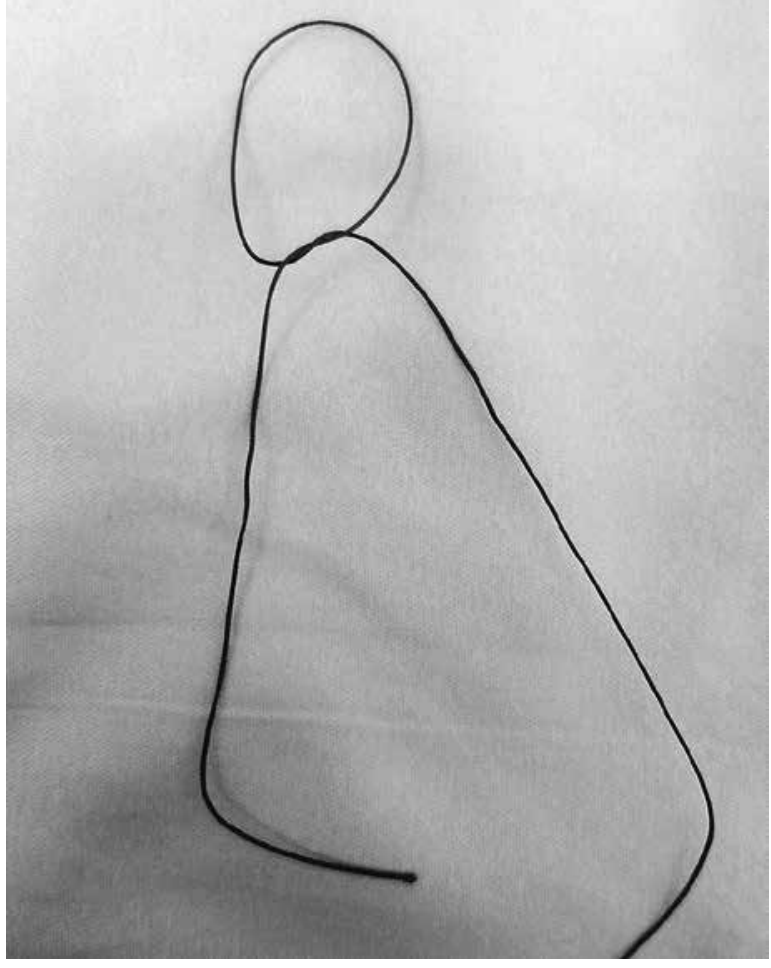

C

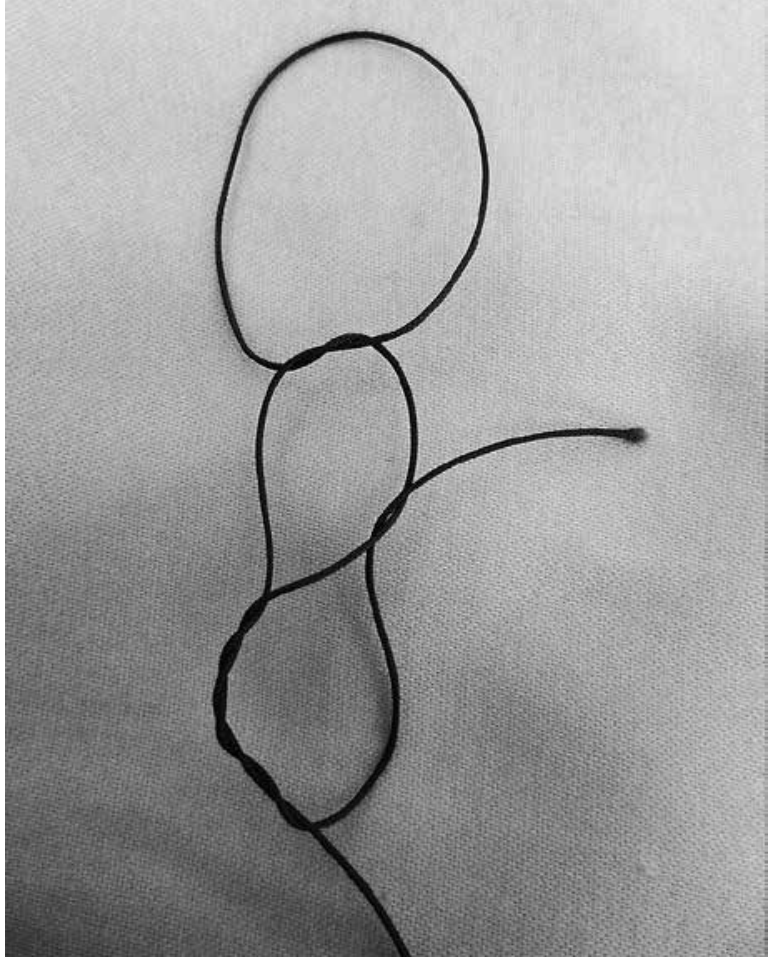

Photo 2. Making of loop
B

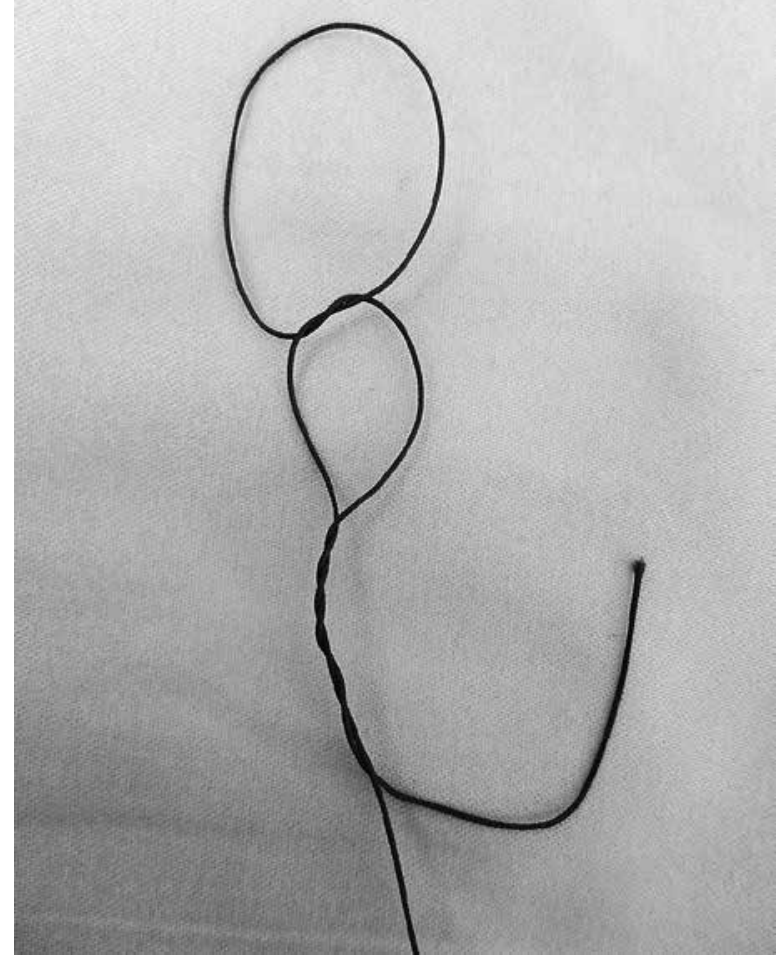

D

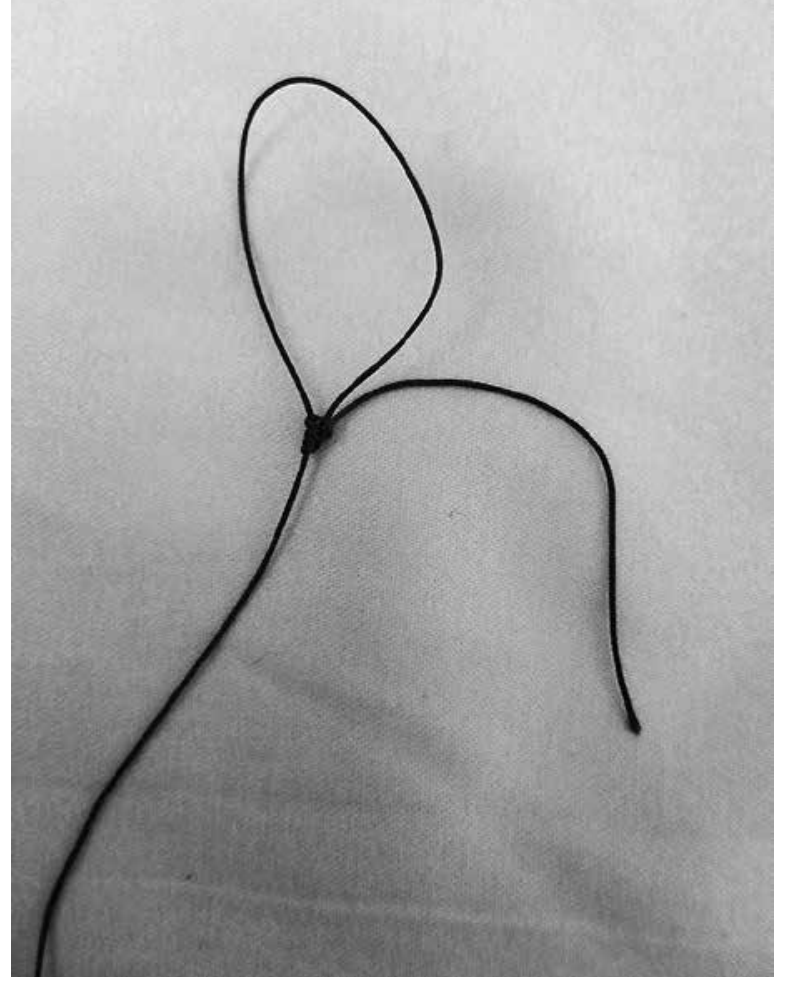


sorbable polymeric clips is safer and cheaper than a stapler [6]. But these clips are not appropriate for patients who have a stump diameter more than $1 \mathrm{~cm}$. Arcovedo et al. compared an extracorporeal sliding knot with a stapler and detected just one intraabdominal abscess among 63 patients in whom an extracorporeal sliding knot was used. So the authors concluded that the extracorporeal sliding knot method is a safe and cheaper way for closing the stump of the appendix [13]. Kiudelis et al. compared intracorporeal knotting with invaginating suture used in 40 patients with endoloop used in 112 patients. In the first group intraabdominal infection was detected in just 2 patients. This ratio is similar to the second group. So the authors concluded that intracorporeal knotting with the invaginating suture method is a safe and cheaper way for closing the stump of the appendix [14]. Yildiz et al. compared endoloop and hand-made endoloop which was similar to the loop that we used in our study. Intraabdominal abscess developed in one patient among 57 patients who had been using a handmade loop and in one patient among 41 patients using endoloop. As a result they concluded handmade loop usage is cheaper [5].

Two hand-made loops from polyglactin cost approximately one American dollar (USD) in our country. Costs of stapler, two endoloops, and two clips are 150 USD, 100 USD, and 7 USD respectively. So the hand-made loop is cheaper than all of them.

In our study, most of the patients are male but the ratio is lower than in other series. This is due to the manner of patient selection by the authors. In female patients, LA was preferred for cosmetic reasons.

In our study, a hand-made loop was used in all patients whatever the diameter of the appendix was. Leakage from the stump or cecal fistula did not develop. Just in two patients an intraabdominal abscess developed. In reoperation of these patients, an abscess was observed in the Douglas pouch. The stump of the appendix was observed as normal; no displacement of loops was detected. Intraabdominal abscess formation rate after LA is $2-4 \%$, which is higher than open appendectomy [13-17]. This may be due to insufficient treatment of local peritonitis laparoscopically. There is no relation between abscess formation and the way used for closure of the stump of the appendix $[5,6,18]$. In our study, like other series, two intraabdominal abscesses and one surgical wound infection out of 61 patients were detected.

\section{Conclusions}

Laparoscopic appendectomy by closing the stump of the appendix with a hand-made loop is a cheaper, safe and easy way for treatment of acute appendicitis. As well as usage in different surgical operations, the hand-made loop can also be used in LA safely.

\section{References}

1. Guller U, Hervey S, Purves H, et al. Laparoscopic versus open appendectomy: outcomes comparison based on a large administrative database. Ann Surg 2004; 239: 43-52.

2. Aziz O, Athanasiou T, Tekkis PP, et al. Laparoscopic versus open appendectomy in children: a meta-analysis. Ann Surg 2006; 243: 17-27.

3. Rickert A, Bönninghoff R, Post S, et al. Appendix stump closure with titanium clips in laparoscopic appendectomy. Langenbecks Arch Surg 2012; 397: 327-31.

4. Kehagias I, Karamanakos SN, Panagiotopoulos S, et al. Laparoscopic versus open appendectomy: which way to go? World J Gastroenterol 2008; 21: 4909-14.

5. Yildiz F, Terzi A, Coban S, et al. The handmade endoloop technique. A simple and cheap technique for laparoscopic appendectomy. Saudi Med J 2009; 30; 224-7.

6. Partecke LI, Kessler W, von Bernstorff W, et al. Laparoscopic appendectomy using a single polymeric clip to close the appendicular stump. Langenbecks Arch Surg 2010; 395: 1077-82.

7. Shimi SM, Lirici M, Vander Velpen G, Cuschieri A. Comparative study of the holding strength of slipknots using absorbable and nonabsorbable ligature materials. Surg Endosc 1994; 8: 1285-91.

8. Fallahzadeh $\mathrm{H}$. Should a laparoscopic appendectomy be done? Am Surg 1998; 64: 231-3.

9. McGrath B, Buckius MT, Grim R, et al. Economics of appendicitis: cost trend analysis of laparoscopic versus open appendectomy from 1998 to 2008. J Surg Res 2011; 171: 161-8.

10. Gołębiewski A, Łosin M, Murawski $M$, et al. One, two or three port appendectomy - a rational approach. Videosurgery Miniinv 2013; 8: 226-31.

11. Gomes CA, Nunes TA, Soares C Jr, Gomes CC. The appendiceal stump closure during laparoscopy: historical, surgical, and future perspectives. Surg Laparosc Endosc Percutan Tech 2012; 22: 1-4.

12. Partecke LI, Kessler W, Patrzyk M, et al. Comparison among different closure methods of the appendicular stump in laparoscopic appendectomy. Surg Technol Int 2011; 21: 85-91.

13. Arcovedo R, Barrera H, Reyes HS. Securing the appendiceal stump with the Gea extracorporeal sliding knot during laparoscopic appendectomy is safe and economical. Surg Endoscop 2007; 21; 1764-7.

14. Kiudelis M, Ignatavicius P, Zviniene K, Grizas S. Analysis of intracorporeal knotting with invaginating suture versus endoloops 
in appendiceal stump closure. Videosurgery Miniinv 2013; 8: 69-73.

15. Paik PS, Towson JA, Anthone GJ, et al. Intra-abdominal abscesses following laparoscopic and open appendectomies. J Gastrointest Surg 1997; 2: 188-92.

16. Katkhouda N, Mason RJ, Towfigh S, et al. Laparoscopic versus open appendectomy: a prospective randomized double-blind study. Ann Surg 2005; 242: 439-48.

17. Kenig J, Richter P. The need for culture swabs in laparoscopically treated appendicitis. Videosurgery Miniinv 2013; 8: 310-4.

18. Lim SG, Ahn EJ, Kim SY, et al. A clinical comparison of laparoscopic versus open appendectomy for complicated appendicitis. J Korean Soc Coloproctol 2011; 27: 293-7.

Received: 27.07.2013, accepted: 31.08.2013. 